\title{
Verminephrobacter eiseniae gen. nov., sp. nov., a nephridial symbiont of the earthworm Eisenia foetida (Savigny)
}

\author{
Correspondence \\ David A. Stahl \\ dastahl@u.washington.edu
}

\author{
Nicolás Pinel, ${ }^{1}$ Seana K. Davidson ${ }^{2}$ and David A. Stahl ${ }^{1,2}$ \\ ${ }^{1}$ Department of Microbiology, University of Washington, Seattle, WA 98195-7242, USA \\ ${ }^{2}$ Department of Civil and Environmental Engineering, University of Washington, Seattle, WA 98195- \\ 2700, USA
}

\begin{abstract}
A Gram-negative, flagellated, heterotrophic, catalase-negative, rod-shaped bacterium previously identified as an earthworm symbiont was isolated from nephridia of the earthworm Eisenia foetida. Comparisons of $16 \mathrm{~S}$ rRNA gene sequences indicated its relatedness to the betaproteobacteria genus Acidovorax and the novel isolates shared 92-94\% sequence similarity with recognized species of this genus. Gene sequence phylogenies revealed that the group of earthworm symbionts formed a cohesive and independent clade. The DNA G+C content was $67.0 \pm 0.2 \mathrm{~mol} \%$. Major fatty acids were $\mathrm{C}_{16: 0}, \mathrm{C}_{16: 1} \omega 7 \mathrm{c}$ and $\mathrm{C}_{17: 0}$ cyclo. While capable of growing in fully aerated media, all isolates favoured low oxygen concentrations and all required biotin or a mix of amino acids in order to grow on defined mineral media. Based on phylogenies inferred from three housekeeping gene sequences (gap, recA and rpoC), DNA-DNA hybridization values, the unique ecology and the distinct physiology of the novel strains, the new genus Verminephrobacter gen. nov. is proposed for the earthworm nephridial symbionts. The name Verminephrobacter eiseniae sp. nov. is proposed for the type species with strain EF01-2 ${ }^{\top}$ $\left(=\right.$ ATCC BAA $-1489^{\top}=$ DSM $\left.19286^{\top}\right)$ as the type strain of the type species.
\end{abstract}

The presence of rod-shaped bacteria in the nephridia (excretory organs) of several species of lumbricid earthworms (Annelida: Oligochaeta: Crassiclitellata Jamieson, 1988; Lumbricidae Claus 1876) was initially reported in light microscopy studies by Knop (1926). Subsequent

\footnotetext{
Abbreviations: ACM, Acidovorax complex medium; ACMP, ACM Phytagel; CFA, cyclic fatty acids; CIA, chloroform-isoamyl alcohol; FAME, fatty acid methyl esters; FISH, fluorescence in situ hybridization; ML, maximum-likelihood; MLST, multilocus sequence typing; MP, maximum-parsimony; NJ, neighbour-joining; PCIA, phenol/chloroformisoamyl alcohol; PFGE, pulsed field gel electrophoresis; PHB, polyhydroxybutyrate; TEM, transmission electron microscopy.

The GenBank/EMBL/DDBJ accession numbers for the 16S rRNA gene sequences of Verminephrobacter eiseniae isolates EF01-1, EF01-2 ${ }^{\top}$, EF02-2, EF03-1, EF03-2, EF04-1, EF05-1 and EF05-2 are D0327662, DQ327663, D0327664, DQ327665, D0327666, DQ327667, DQ327668 and DQ327669, respectively. The GenBank accession numbers for the MLST sequences are EU165058-88 and EU350960.

Details of the methods used for soil DNA surveys and siderophore production and uptake are available as supplementary methods with the online version of this paper. Also available are supplementary tables giving the results of DNA-DNA hybridization studies and the pairwise sequence identities of $16 \mathrm{~S}$ rRNA sequences. Supplementary figures show additional phylogenetic trees, the reactions in 'deep phytagel' tubes, vitamin requirements and siderophore production assays for the strains studied.
}

studies identified the dominant bacteria, localized predominantly in the ampullum (the medial region of the nephridial second loop), as Gram-negative organisms (Scott \& Musgrave, 1971) closely related to the betaproteobacterial genus Acidovorax (Schramm et al., 2003). Unique $16 \mathrm{~S}$ rRNA betaproteobacterial ribotypes have been recovered from different earthworm species. The transmission of the symbiont through its deposition in the egg capsule has been recently demonstrated in the earthworm Eisenia foetida Savigny by Davidson \& Stahl (2006).

Acidovorax-like 16S rRNA gene sequences are frequently recovered from wastewater treatment plants and other aquatic environments (Schweitzer et al., 2001; Hoshino et al., 2005; Manefield et al., 2005). The genus Acidovorax includes species isolated from soil and sludge (Willems et al., 1990; Schulze et al., 1999; Heylen et al., 2008), in addition to a group of plant pathogens with a varied host range (Willems et al., 1992; Gardan et al., 2000, 2003). The present study reports the isolation and characterization of a relative of the genus Acidovorax from the nephridia of E. foetida. This is the first representative of a group affiliated with the genus that forms a recognizably stable association with animal hosts. Based on the unique ecology of this organism relative to other known species of the genus Acidovorax and its distinct characteristics reported herein, we propose the designation of the genus 
Verminephrobacter gen. nov. to include betaproteobacterial denizens of lumbricid earthworm nephridia. The isolates recovered from $E$. foetida are designated as representing the type species for the new genus and the name Verminephrobacter eiseniae sp. nov. is proposed.

Cultures were regularly initiated from frozen stocks and were maintained in Acidovorax complex medium [ACM; containing $\mathrm{l}^{-1}$ : $0.5 \mathrm{~g}$ yeast extract (Difco-Becton Dickinson), $1.0 \mathrm{~g}$ Casamino acids (Difco), $2.0 \mathrm{~g}$ pyruvic acid, $2.0 \mathrm{~g}$ L-glutamine, $0.3 \mathrm{~g} \mathrm{KH}_{2} \mathrm{PO}_{4}, 0.3 \mathrm{~g} \mathrm{MgSO}_{4}$ and 2.0 g MOPS, with the $\mathrm{pH}$ adjusted to $7.2-7.3$ with $5 \mathrm{M} \mathrm{KOH}$ before autoclaving]. The following gelling agents were tested: Bacto agar (Difco), Noble agar (Sigma Aldrich), agarose (JT Baker-Mallinckrodt Baker) and Phytagel (Sigma Aldrich). Only Phytagel afforded consistent isolation and growth of nephridial bacteria. Plates contained $1.5 \%$ Phytagel. Basal defined media consisted of $\left(1^{-1}\right.$ distilled water $): 10 \mathrm{ml} 100 \times$ mineral salts solution (unless noted otherwise, all chemicals were obtained from Sigma Aldrich; $1^{-1}: 250 \mathrm{~g} \mathrm{NaCl}, 50 \mathrm{~g}$ $\left.\mathrm{KH}_{2} \mathrm{PO}_{4}, 10 \mathrm{~g} \mathrm{MgSO}_{4}, 1 \mathrm{~g} \mathrm{CaCl}_{2}\right), 1 \mathrm{ml} \mathrm{SL} 12$ trace metal solution ( $1^{-1}: 3$ g sodium EDTA, $1.1 \mathrm{~g} \mathrm{FeCl}_{2}, 6 \mathrm{mg} \mathrm{H}_{3} \mathrm{BO}_{3}$,

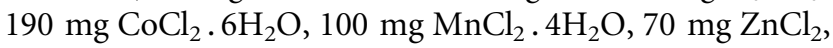
$36 \mathrm{mg} \mathrm{Na} \mathrm{NoO}_{4} \cdot 2 \mathrm{H}_{2} \mathrm{O}, 24 \mathrm{mg} \mathrm{NiCl} \cdot 6 \mathrm{H}_{2} \mathrm{O}$ and $2 \mathrm{mg}$ $\left.\mathrm{CuCl}_{2} \cdot 2 \mathrm{H}_{2} \mathrm{O}\right)$ and $1 \mathrm{ml} 1000 \times$ vitamin solution $\left(\mathrm{l}^{-1}\right.$ : $50 \mathrm{mg}$ p-aminobenzoic acid, $20 \mathrm{mg}$ folic acid, $50 \mathrm{mg}$ nicotinic acid, $50 \mathrm{mg}$ calcium pantothenate, $50 \mathrm{mg}$ riboflavin, $50 \mathrm{mg}$ thiamine hydrochloride, $100 \mathrm{mg}$ pyridoxine, $50 \mathrm{mg}$ thioctic acid, $5 \mathrm{mg}$ cyanocobalamin and $1 \mathrm{mg}$ biotin). The medium was buffered with $20 \mathrm{mM}$ MOPS at $\mathrm{pH}$ 7.2-7.3. Carbon and nitrogen sources were added as appropriate.

Isolate EF01-2 ${ }^{\mathrm{T}}$ was designated as the type strain of the novel isolates deposited. Strain EF05-2 was also deposited as a reference strain (=DSM 19250). The following reference strains were used for comparisons: Acidovorax anthurii DSM $16745^{\mathrm{T}}$, A. avenae subsp. avenae DSM $7227^{\mathrm{T}}$, A. avenae subsp. citrulli AAC00-1, A. defluvii DSM $12644^{\mathrm{T}}$, A. delafieldii ATCC $17505^{\mathrm{T}}$, A. facilis ATCC $11228^{\mathrm{T}}$, A. konjaci DSM $7481^{\mathrm{T}}$, A. temperans ATCC $49665^{\mathrm{T}}$ and A. valerianellae DSM $16619^{\mathrm{T}}$.

In order to isolate and quantify the nephridial bacteria, earthworms were maintained as previously described by Davidson \& Stahl (2006). For dissection, specimens were anaesthetized in $1 \times$ PBS with $4 \%(\mathrm{v} / \mathrm{v})$ ethanol. The body wall was separated along a dorsal, longitudinal incision and held in place with dissection pins. The intestines were removed and the body tissues were rinsed with sterile $1 \times$ $\mathrm{PBS} / 4 \%$ ethanol. Nephridia (20-50) were removed with forceps, rinsed once in sterile $1 \times$ PBS and pooled into a microcentrifuge tube with sterile $1 \times$ PBS. Nephridia were crushed with a sterile micro pestle, diluted and plated. Plates were sealed with Parafilm and incubated at room temperature $\left(\sim 25^{\circ} \mathrm{C}\right)$. Colonies of the predominant morphology on the highest dilution plates presenting growth were streaked for purity and incubated as above. The resulting colonies were screened by fluorescence in situ hybridization (FISH) using the Acidovorax-specific probe LSB145 (Schweitzer et al., 2001) and then inoculated into ACM broth. Cultures were incubated at room temperature with agitation in a rotary shaker at 250 r.p.m. After 610 days, the identity of the isolates was confirmed by FISH and $16 \mathrm{~S}$ rRNA gene sequencing. Similar isolation procedures were used for the isolation of symbionts from the earthworm species Lumbricus terrestris and Aporrectodea longa ( $\mathrm{N}$. Pinel, unpublished).

After 15-20 days incubation at room temperature, ACMPhytagel (ACMP) plates inoculated with the $10^{-4}-10^{-5}$ dilutions from nephridial suspensions presented, almost exclusively, circular, convex colonies of $0.5-2 \mathrm{~mm}$ in diameter, with entire or lightly erose margins and a light bisque to peach colour. The colonies showed negative Gram staining (not shown) and positive hybridizations to the LSB145 oligonucleotide probe.

Material for the determination of the number of colony forming units (c.f.u.) per nephridium was prepared as above from four sexually mature (clitellated) worms. Serial dilutions were plated on ACMP plates in triplicate or quadruplicate. Colony counts indicated a mean bacterial density of $3.3 \pm 1.9 \times 10^{5}$ c.f.u. per E. foetida nephridium.

For phylogenetic analyses, chromosomal DNA was extracted and purified by the Marmur protocol (Marmur, 1963) with the following modifications after cell lysis: the lysate was extracted once with Tris-SDS buffer-saturated phenol for $1 \mathrm{~h}$ (Tris-SDS buffer; $100 \mathrm{mM}$ Tris/HCl pH 8.0; $50 \mathrm{mM}$ EDTA pH 8.0; $100 \mathrm{mM} \mathrm{NaCl}$; $1 \% \mathrm{w} / \mathrm{v}$ SDS). The aqueous phase was then extracted with phenol/chloroform-isoamyl alcohol (PCIA; $25: 24: 1$ ) and chloroform-isoamyl alcohol (CIA; 24:1). DNA was precipitated with one volume of 2-propanol, resuspended in $1 \times$ TE buffer and treated with RNase A, followed by PCIA and CIA extractions, ethanol precipitation and resuspension in $1 \times$ TE.

The nearly complete $16 \mathrm{~S}$ rRNA gene was amplified and sequenced according to standard methods with primers GM3 and GM4 (Muyzer et al., 1993). The resultant sequences (1455-1463 bp) for all eight isolates were aligned in ARB (Ludwig et al., 2004) against the Ribosomal Database Project (RDP) database (Cole et al., 2003) with manual refinement. The primer pairs gapf-1 (5'-AAYGGYTTYGGCCGCATC-3')/gapr-1 (5' -CACSCGCACCATYTCCAG-3'), recAf-1 (5'-GGCAAGGGCACSATCATG-3')/recAr-1 (5'-CGTTGWAGGCRTACCAGGC$\left.3^{\prime}\right)$, and rpoCf- 1 (5'-CCTGTTCAAGCAATTCACG- $\left.3^{\prime}\right) /$ rpoCr-1 (5'-ACCTTGTTGTAGCGCTCG-3') were used to amplify and sequence fragments from glyceraldehyde3-phosphate dehydrogenase (type I; gap; $\sim 859 \mathrm{nt}$ ), recA $(\sim 716 \mathrm{nt})$ and the DNA-directed RNA polymerase, beta' subunit $(r p o C)$, respectively, unless the corresponding sequences were available from public databases. Interior sequencing of rpoC was achieved with primers rpoCseqF2 (5'-AGCGCAAGGAATAYGG-3') and rpoC-seqR2 (5'-GAGCACCACGTCYTG-3'); sequences of 1290 nucleo- 
tides were used. Sequence alignments were constructed with CLUSTAL W (Thompson et al., 1994) and refined manually. Maximum-parsimony (MP), evolutionary distance (neighbour-joining; NJ) and maximum-likelihood (ML) phylogenetic analyses were performed in PHYLIP (Felsenstein, 1989).

Among the isolated symbionts, the 16S rRNA gene sequences were $98.5 \pm 0.4 \%$ similar. The symbiont gene sequences were $94.9 \pm 0.5 \%$ similar to those of nephridial clones obtained from other earthworm species, $92.5 \pm 0.5 \%$ similar to those of reported plant pathogens of the genus Acidovorax and $93.3 \pm 0.3 \%$ similar to other species within the genus. Mean $16 \mathrm{~S}$ rRNA gene sequence similarity values among plant-pathogenic and non-symbiotic Acidovorax species ranged from 96.2-97.4\%. The E. foetida isolates formed a monophyletic group within the clade of earthworm nephridial symbionts. All 16S rRNA gene phylogenies (Fig. 1a, NJ; MP and ML not shown) supported the cohesion of the novel symbiotic group, but allowed only limited resolution of the branching pattern among the sequences examined. Three well-defined groups were supported by phylogenetic reconstructions with rpoC or concatenated recA/gap gene sequences (Fig. 1b, c and see Supplementary Fig. S1 in IJSEM Online). One of the groups encompassed the earthworm symbionts, another included most of the known plant pathogenic species of the genus Acidovorax and a third comprised most of the remaining species. The branching order of these three groups could not be confidently established (bootstrap support above $50 \%$ ) from the inferred topologies.

The DNA $\mathrm{G}+\mathrm{C}$ content was determined as previously described (Mesbah et al., 1989) with the following modifications: DNA was digested with $10 \mathrm{U}$ mung bean nuclease and 50 U S1 nuclease. Separation of nucleosides was performed isocratically for 15 min with a flow rate of $1 \mathrm{ml} \mathrm{min}{ }^{-1}$ on a mobile phase of $95 \% 20 \mathrm{mM}$ triethylamine phosphate (pH 5.1)/5\% methanol, through a Zorbax SB-C18 column $(4.6 \times 150 \mathrm{~mm} ; 5.0 \mu \mathrm{m}$ particle size; Agilent Technologies). DNA samples from $A$. temperans and $A$. delafieldii were used as controls. The DNA G + C content (determined for isolates EF01-1, EF01$2^{\mathrm{T}}$, EF02-2 and EF05-1) was $67.0 \pm 0.2 \mathrm{~mol} \%$, well within the $60-72 \mathrm{~mol} \%$ values reported for other species of the genus Acidovorax (Schulze et al., 1999; Gardan et al., 2000, 2003), and in close agreement with the $65.2 \mathrm{~mol} \%$ observed for the genome sequence of isolate EF01-2 (unpublished observations).

DNA-DNA hybridizations were conducted with the microtitre plate technique (Ezaki et al., 1989) as described by Willems et al., (2001), and modified as follows: before labelling with photobiotin, probe DNA was fragmented through nebulizers (Invitrogen) under a stream of $\mathrm{N}_{2}$ at a pressure of 28 p.s.i. for $1.5 \mathrm{~min}$, yielding a final fragment range of 250-2000 kb. Probe DNA was labelled under direct sunlight for $1 \mathrm{~h}$ on ice. The hybridization temperature was $50{ }^{\circ} \mathrm{C}$. The chromogenic substrate 2-nitrophenyl- $\beta$-galactopyranoside (ONPG) replaced the fluorogenic substrate 4-methylumberlliferone used in the original protocol. After a $30 \mathrm{~min}$ incubation at $37^{\circ} \mathrm{C}$, the chromogenic reactions were developed for at least $15 \mathrm{~min}$ with $10 \mu \mathrm{l} 2 \mathrm{M}$ sodium carbonate. Hybridization values were calculated from the percent absorbance at $405 \mathrm{~nm}$, with the homologous reaction representing $100 \%$. Salmon DNA was immobilized as a background absorbance control. All hybridizations were run in triplicate wells on at least three plates. The mean standard deviation of the method was $\pm 7.6 \%$. The complete results of the DNADNA hybridization experiments are provided in Supplementary Table S1 (see IJSEM Online). The mean DNA-DNA hybridization values were $99 \pm 2 \%$ (range 94$107 \%$ ) among all eight isolated symbionts. In contrast, mean reassociation values to type species of the genus Acidovorax ranged from 8 to $27 \%$. The DNA-DNA hybridization results supported the status of the isolated symbionts as representing a novel species. While Willems et al. (2001) used the reciprocal hybridizations as internal controls, we found that in some cases reciprocal hybridization gave consistently disparate values, possibly reflecting differences in genome sizes among the species included in the assays. The discrepancies did not alter the main conclusion from our results.

In order to examine the DNA molecules of the isolated strains, pulsed field gel electrophoresis (PFGE) of genomic DNA was performed on a CHEF-DR III system (Bio-Rad Laboratories). DNA plugs were prepared as per the protocol given in the instrument documentation, with $\sim 5.0 \times 10^{8}$ cells per agarose plug.

For detection of large extrachromosomal molecules, DNA plugs were treated with S1 nuclease as previously described (Barton et al., 1995) and examined using PFGE. The alkaline lysis miniprep protocol was used for extracting small plasmids. An extrachromosomal DNA molecule was detected in isolates EF01-1, EF01-2 ${ }^{\mathrm{T}}$, EF02-2 and EF04-1 (data not shown), which migrated as a $98 \mathrm{~kb}$ molecule from untreated DNA plugs and as a $35 \mathrm{~kb}$ molecule after S1-linearization (not shown). By sequencing the genome of isolate EF01-2, this molecule was confirmed as a circular, $31.2 \mathrm{~kb}$ plasmid (unpublished observations). Four extrachromosomal molecules were observed in A. temperans DNA preparations, with migration rates suggestive of 375 , 155, 96 and $47 \mathrm{~kb}$ before, or 212, 155, 55 and $29 \mathrm{~kb}$ after S1 linearization, respectively (not shown). Additional extrachromosomal molecules were detected through PFGE for A. defluvii (212 and $169 \mathrm{~kb}$ ) and A. facilis (193 kb), but only after S1 linearization. A $2.3 \mathrm{~kb}$ plasmid was isolated from $A$. defluvii (not shown).

For cellular fatty acid analysis, fatty acid methyl esters (FAME) were extracted and chromatographed by the Microbial Identification Company (MIDI; Microbial ID; Smibert \& Krieg, 1994) according to standard protocols. Cultures of isolated symbionts and the type strains of $A$. avenae subsp. avenae, A. facilis, A. konjaci and A. temperans 
(a)

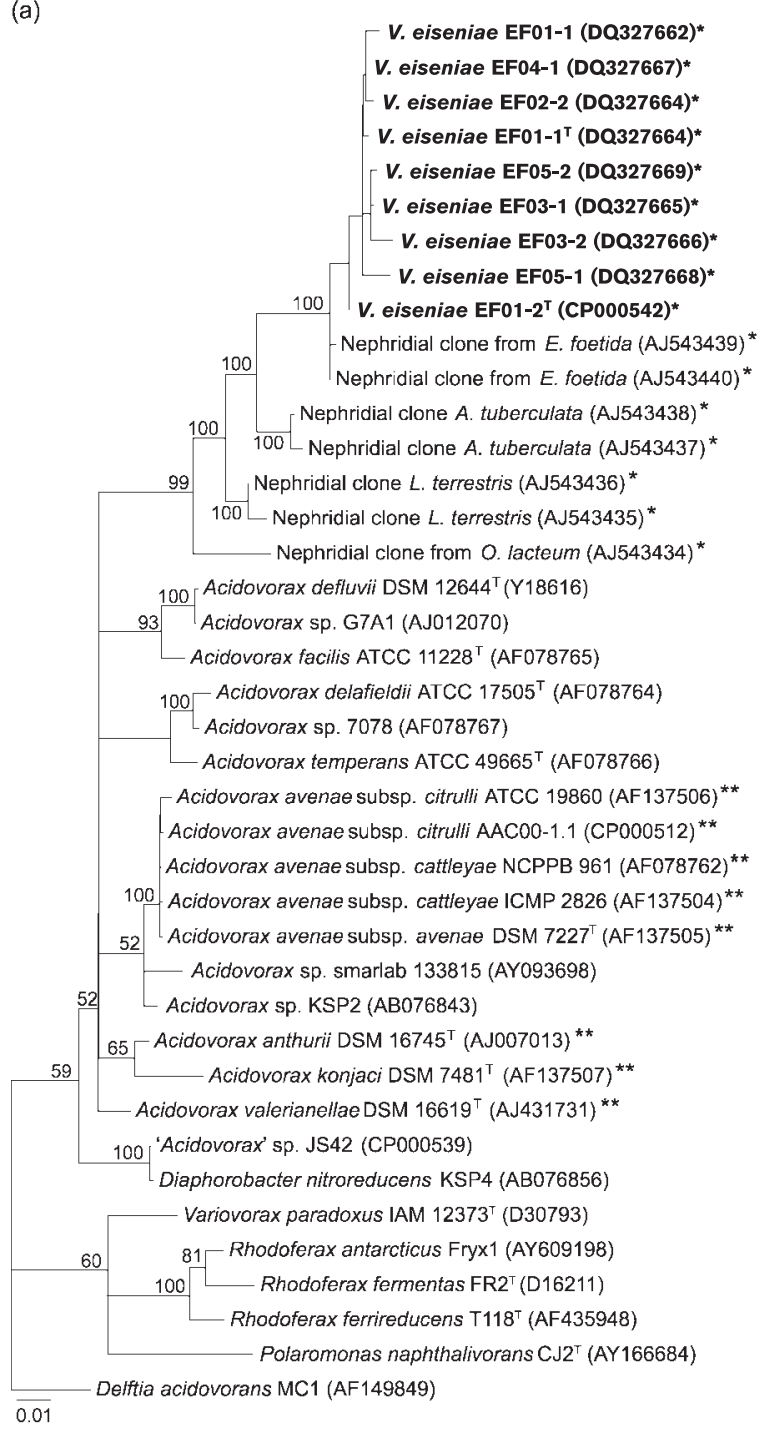

(b)

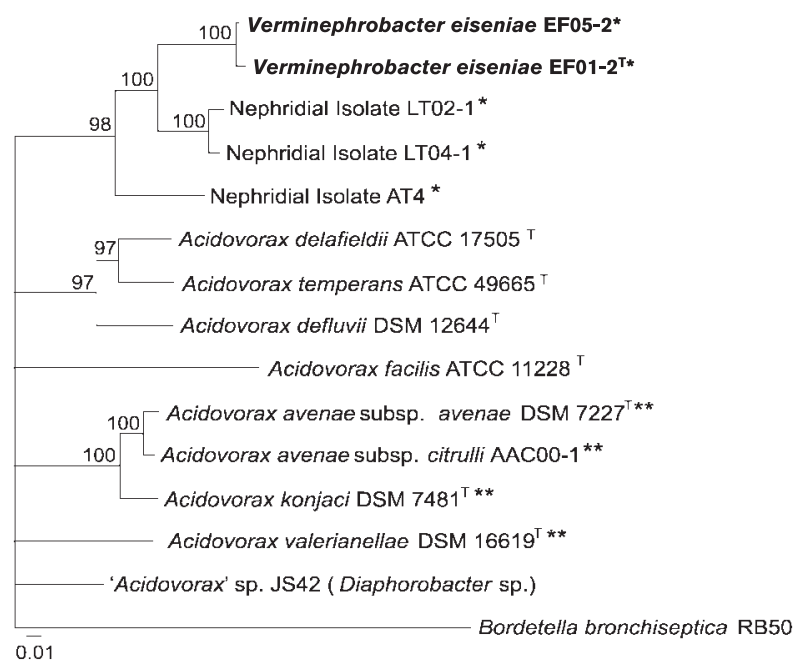

(c)

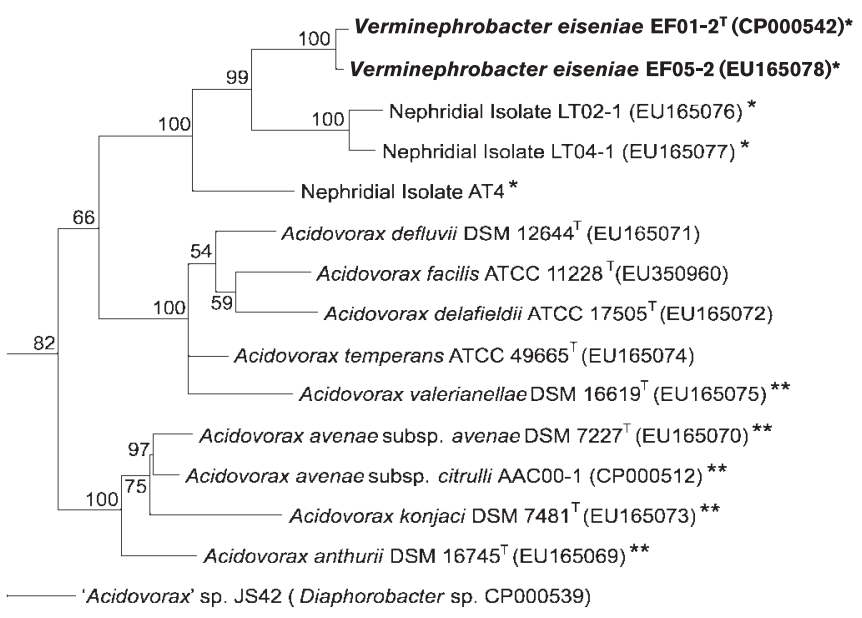

$\overline{\overline{0.01}}$

Fig. 1. Neighbour-joining phylogenetic reconstructions from (a) nearly complete 16S rRNA gene sequences; (b) concatenated partial recA/gap nucleotide sequences; (c) partial rpoC nucleotide sequences. Bootstrap values were derived from 1000 replicates. Nodes with $<50 \%$ bootstrap support were eliminated. Entries in bold type correspond to isolates described in this report. *Organisms associated with earthworm nephridia; ** reported plant-pathogenic species of the genus Acidovorax. Bordetella bronchiseptica RB50 served as an outgroup in all reconstructions. Trees constructed with maximum-parsimony and maximum-likelihood algorithms are available as supplementary figs in IJSEM Online. 'Acidovorax sp.' JS42 is misnamed in current databases; it is included as it is part of a Verminephrobacter eiseniae sp. nov. comparative genome analysis project (unpublished data). Bars, 1 nucleotide substitution per 100 nucleotides.

(see above) were grown on ACMP plates for either 15 days (isolated symbionts) or $48 \mathrm{~h}$ (other strains of the genus Acidovorax) before biomass was collected. The differences in incubation time reflected differences in growth rate and the time required for obtaining sufficient biomass. To account for growth medium effects, results for the recognized species of the genus Acidovorax were compared with data from Willems et al. $(1990,1992)$. FAME peaks were identified as equivalent chain-length (ECL) and their area expressed as percentages of total peak area. Similarities were calculated using the correlation coefficient algorithm (Bousfield et al., 1983) after removal of peaks with $<1 \%$ total peak area. Cluster analyses were performed with the PC-ORD software package, employing the Sorensen similarity index and the UPGMA and NJ algorithms.

The fatty acid composition profiles for the eight symbiotic isolates had similarity values of $98 \pm 1 \%$, while their similarity to the profiles from the Acidovorax species examined was $91 \pm 1 \%$. The similarity to fatty acid profiles 
reported for other species of the family Comamonadaceae was below $90 \%$ (not shown; Willems et al., 1990, 1992; Schulze et al., 1999). The profiles obtained in this study for the type strains of the reference Acidovorax species growing on ACMP plates and those reported in the literature for the corresponding species differed by less than $1 \%$. The dominant components included peaks with ECL values for palmitic $\left(\mathrm{C}_{16: 0}, 27-31 \%\right)$, palmitoleic $\left(\mathrm{C}_{16: 1}, 16-35 \%\right)$ and cis-9,10-methylenehexadecanoid acid $\left(\mathrm{C}_{17: 0}\right.$ cyclo, 9$26 \%$ ); the latter being exclusive to the isolated symbionts among other reference strains (Table 1). Cyclopropanes (such as $\mathrm{C}_{17: 0}$ cyclo) are derived from the corresponding unsaturated fatty acids (Grogan \& Cronan, 1997), which could explain the reduction in palmitoleic acid in the novel isolates relative to the amounts found in the reference Acidovorax species. Differential expression of cyclic fatty acids (CFA) according to growth state has been observed for many organisms (Grogan \& Cronan, 1997; Könneke \& Widdel, 2003) and their appearance has been hypothesized as a strategy to preserve membrane integrity during starvation (Guckert et al., 1986) as CFA are more refractory to bacterial lipases than their cis-monounsaturated acid precursors. The validity of this explanation for the novel isolates examined in this study, as well as the ability of reference species of the genus Acidovorax to synthesize CFA, remains to be determined.

Morphological and physiological traits of the novel isolates were examined as follows. The minimum doubling time attained by the isolated symbionts on ACM broth at $25{ }^{\circ} \mathrm{C}$ ranged from 6.5 to $14 \mathrm{~h}$, with values distributed bimodally. Plasmid-free (see above) isolates EF03-1, EF03-2, EF05-1 and EF05-2 showed mean doubling times of $6.5 \pm 0.1 \mathrm{~h}$, whereas the remaining isolates showed mean doubling times of $12.1 \pm 2.0 \mathrm{~h}$. Doubling times for reference strains growing on ACM broth ranged from 0.7 to $2.5 \mathrm{~h}$. Doubling times and growth rates were calculated as described by Fuchs \& Kröger (1999).

Cell morphology was examined by phase-contrast and transmission electron microscopy (TEM). For negative staining, cells were suspended in a $10 \mathrm{mM} \mathrm{Mg}_{2} \mathrm{Cl}$ solution. The cell suspension was mixed with an equal volume of $2 \%$ phosphotungstic acid in water and spotted onto coated copper grids. For TEM, cells from late exponential cultures in ACM were fixed in half-strength Karnovsky's fixative $(1 \times$ solution contained $2 \%$ paraformaldehyde and $2.5 \%$ glutaraldehyde) in cacodylate buffer $[0.1 \mathrm{M}$ sodium cacodylate; $10 \mathrm{mM} \mathrm{CaCl}_{2}$ (pH 7.3)] overnight at $4{ }^{\circ} \mathrm{C}$. Fixed cells were rinsed in fresh buffer and mixed with an equal volume of $2 \%$ agarose in double-distilled $\mathrm{H}_{2} \mathrm{O}$. Plugs were counterfixed with $1 \% \mathrm{OsO}_{4}$ in cacodylate buffer for $1 \mathrm{~h}$, dehydrated in an ethanol series and stained with uranyl acetate and lead citrate before sectioning and TEM. For TEM of tissue sections, worms were dissected as above and processed as described by Ballinger et al. (1997) with additional post-fixation staining with $2 \%$ uranyl acetate (Ted Pella) prior to embedding. Gram staining and Nile Blue A staining for detection of cellular polyhydroxybuty-

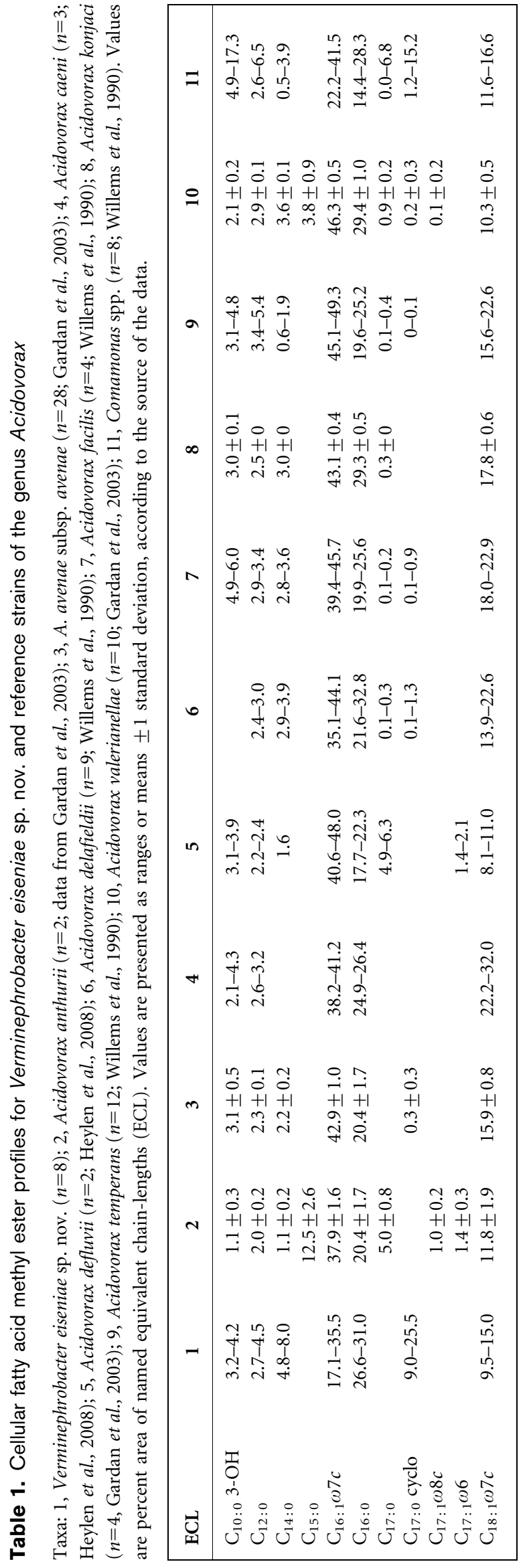


rate $(\mathrm{PHB})$ granules were conducted as described by Smibert \& Krieg (1994).

When examined by phase-contrast optics, cells from liquid cultures appeared as short, rounded rods, $1.5 \pm 0.2 \times$ $0.6 \pm 0.2 \mu \mathrm{m}$ in size and single or in doublets (Fig. 2a). Active motility was not observed although cells were occasionally observed pivoting as if tethered to the glass slide by means of flagella. The presence of polar flagella was confirmed by TEM of negatively stained cells (Fig. 2b). PHB granules were observed in all isolated symbionts grown on ACM broth (not shown). Cells of the cultured symbionts were Gram-negative (not shown).

Catalase tests were performed by adding drops of $3 \%(\mathrm{w} / \mathrm{v})$ hydrogen peroxide to cell suspensions. Oxidase tests were conducted as recommended using a proprietary kit (bioMérieux). All isolated symbionts and other Acidovorax reference strains tested positive for oxidase activity. Catalase activity was positive for the Acidovorax reference strains but was undetectable for all eight of the novel isolates, irrespective of the age of the cultures.

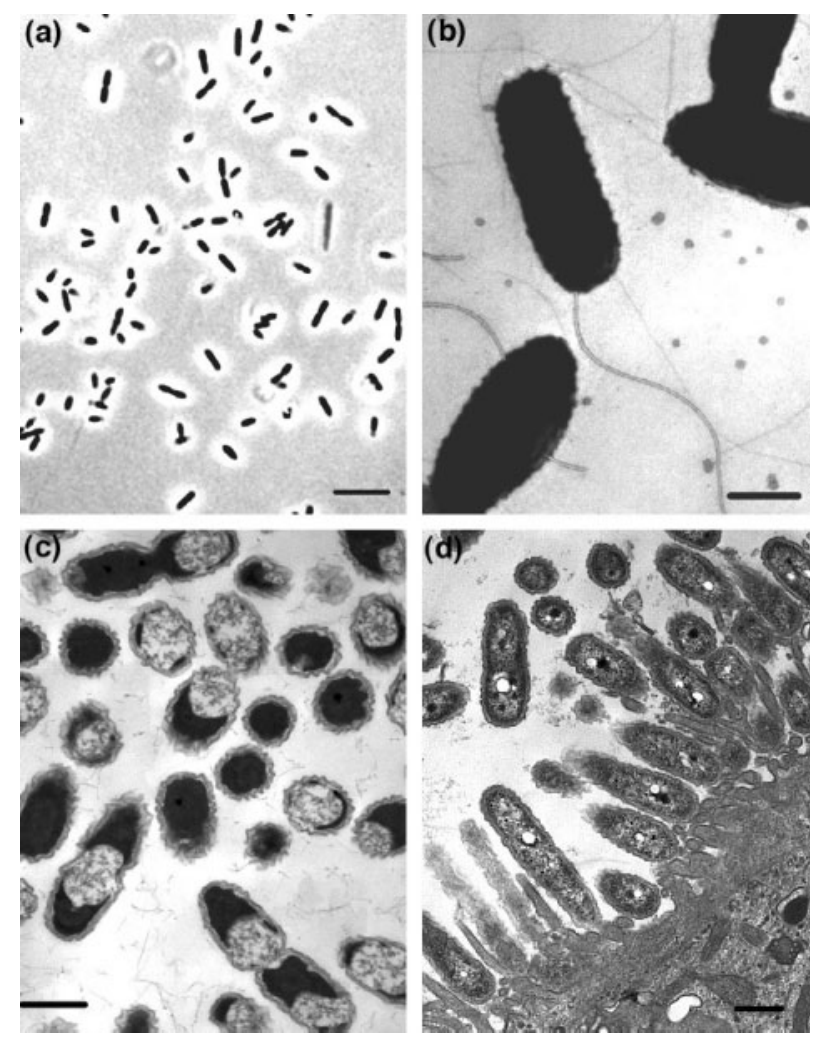

Fig. 2. Micrographs of cells of the novel strains growing on $A C M$ broth. (a) Phase-contrast; (b) negatively stained electron micrograph, revealing flagellated cells; (c) TEM of fixed cells, illustrating electron-light inclusions characteristic of cultured cells; (d) TEM of earthworm tissue section showing cells of Verminephrobacter eiseniae sp. nov. associated with the endothelial microvilli inside the nephridium. Bars, $5 \mu \mathrm{m}$ (a), $0.5 \mu \mathrm{m}$ (b, c, d).
Oxygen relationships were investigated through a 'deep agar' assay (Smibert \& Krieg, 1994), modified by substituting agar with $0.4 \%$ Phytagel and amending the ACM broth with $1 \mathrm{mg} \mathrm{l}^{-1}$ resazurin (redox indicator; $\mathrm{E}^{0}=-51$ ). The tubes were incubated at room temperature $\left(\sim 25^{\circ} \mathrm{C}\right)$ for 15 days. Tested strains were cultured in duplicate in at least two different experiments. The clearpink interface (anoxic/oxic boundary) in cultures inoculated with any of the eight isolated earthworm symbionts migrated upwards from $\sim 2.0 \mathrm{~cm}$ deep $10 \mathrm{~h}$ post-inoculation to $\sim 1.0 \mathrm{~cm}$ deep, where it stabilized after 6-8 days of incubation. After 15 days incubation, a thin horizon of growth was observed at the said depth; the lower clear zone presented undetectable growth, while the pink region displayed light turbidity (see Supplementary Fig. S2 in IJSEM Online). This pattern was also detected in tubes inoculated with $A$. defluvii. In tubes inoculated with the remaining Acidovorax reference species with catalasepositive type strains, the entire tube turned clear 1-2 days post-inoculation and growth was present almost exclusively at the surface of the medium.

The use of alternative electron acceptors was examined using ACM broth amended with $1 \mathrm{mg} \mathrm{l}^{-1}$ resazurin and, where appropriate, $10 \mathrm{mM}$ (final concentration) of sodium fumarate, $\mathrm{KNO}_{3}$ or DMSO. Media were rendered anoxic by storage inside an anaerobic glove box for at least $8 \mathrm{~h}$ before dispensing into degassed Balch tubes. Before autoclaving, sealed tubes were gassed with $\mathrm{N}_{2} / \mathrm{CO}_{2}(95 / 5 \%)$. The head space was similarly replaced after autoclaving while the media temperature was maintained at $80{ }^{\circ} \mathrm{C}$. Cooled tubes were inoculated $(1: 50)$ inside the anaerobic glove box with cultures growing on ACM broth and incubated as above. Anoxic conditions were confirmed by the absence of pink colouration. Oxic controls were treated similarly, but exposed to the atmosphere. Growth was defined as final $\mathrm{OD}_{600}>0.2$. None of the novel symbiotic strains tested were capable of growth on ACM under anoxic conditions, even in the presence of the alternative electron acceptors tested. Recognized species of the genus Acidovorax, except for A. valerianellae (Gardan et al., 2003) are capable of respiring nitrate.

Determinations of optimal temperature and $\mathrm{NaCl}$ concentration for growth were conducted on $2.5 \mathrm{ml}$ of basal defined media with D-mannose $(10 \mathrm{mM})$ and L-glutamine $(5 \mathrm{mM})$ as carbon and nitrogen sources, respectively. These organic substrates have been shown previously to support good growth of the symbionts in defined media (N. Pinel, unpublished data). Cultures for temperature experiments were incubated at $4,15,25,30,33$ and $37^{\circ} \mathrm{C}$; all other incubations were at $25{ }^{\circ} \mathrm{C}$. For determination of the optimum $\mathrm{pH}$, L-glutamine was replaced by an equal concentration of urea and MOPS buffer (used for $\mathrm{pH}$ values 6.9-7.8) was substituted by MES, HEPES and TRIS buffers for $\mathrm{pH}$ ranges of 5.6-6.6, 7.8-8.2, and 8.2-9.0, respectively. Overlapping $\mathrm{pH}$ values were included to account for buffer effects on growth rate. 
The isolated symbionts grew at temperatures between 10 and $33{ }^{\circ} \mathrm{C}$, with the optimum temperature (highest growth rates) between 25 and $28{ }^{\circ} \mathrm{C}$. $\mathrm{NaCl}$ in the medium was not required for growth; the symbionts grew optimally at a sodium concentration between 50 and $60 \mathrm{mM}$. The latter values agreed with the $\mathrm{NaCl}$ equivalent concentration measured from the urine of the earthworm Lumbricus terrestris at the ampullar region of the nephridia (Ramsay, 1949). Maximum yield (maximum $\mathrm{OD}_{600}$ ) increased slightly with increasing $\mathrm{NaCl}$ up to $90 \mathrm{mM}$, but dropped significantly at the next tested concentration $(120 \mathrm{mM})$. Growth was observed in media at $\mathrm{pH}$ values between 6 and 8.2. The highest growth rates and maximum $\mathrm{OD}_{600}$ values were observed at $\mathrm{pH}$ values between 7.5 and 8.2, depending on the isolate, but sharp optima were not apparent. Since Tris buffer appeared to inhibit the growth of the novel isolates, an upper $\mathrm{pH}$ limit for growth was not determined.

API CH50 galleries (bioMérieux) were used to test the growth of the isolates on a set of 49 carbohydrates over an $80 \mathrm{~h}$ incubation period. Media for testing growth on additional carbon and nitrogen sources contained basal defined medium amended with $10 \mathrm{mM}$ of the corresponding carbon or nitrogen source from prepared stocks. The $\mathrm{pH}$ was adjusted to between 7.0 and 7.5 if necessary. The medium was filter-sterilized through $0.2 \mu \mathrm{m}$ membrane filters and aliquoted $(200 \mu \mathrm{l}$ per well $)$ into 96-well microtitre plates. Growth on each substrate was evaluated in triplicate wells on the same plate for each strain. Carbon- or nitrogen-free controls for each strain and uninoculated controls for each substrate were included in every plate. $\beta$-Hydroxybutyrate $(20 \mathrm{mM})$ or ammonium chloride $(10 \mathrm{mM})$ served as carbon or nitrogen sources, respectively, for the nitrogen and carbon assimilation tests; ammonium chloride was omitted when testing for growth on amino acids. Cells from mid-exponential ACM cultures were recovered by centrifugation, rinsed once with carbonand nitrogen-free basal medium and resuspended in fresh carbon- and nitrogen-free medium to an approximate $\mathrm{OD}_{600}$ of 1.0. A $10 \mu \mathrm{l}$ sample of this cell suspension was used to inoculate each well. Plates were sealed with Parafilm to reduce evaporation and incubated at room temperature in the dark on an orbital shaker at 200 r.p.m. Plates of Acidovorax reference strains were incubated for 4 days; plates inoculated with the isolated symbionts were incubated for 10 days. Final $\mathrm{OD}_{600}$ was measured using a microtitre plate reader. Positive growth was defined as a final $\mathrm{OD}_{600}>0.05$ after subtraction of the corresponding value from the carbon- or nitrogen-free control. Each substrate was tested using at least two independent replicate plates. Results for the novel symbiotic strains and diagnostic carbon sources are presented in Table 2. A notable difference between the nephridial isolates and freeliving species of the genus Acidovorax was the greater range of carbohydrates utilized by the symbionts. This may be a characteristic that reflects their symbiotic environment since carbohydrates such as mannose, fucose and galactose, are common in glycosylated surfaces such as those that may be present in the ampullar epithelium. The use of sugar residues from host surface glycans as a source of energy has been documented in other symbiotic systems (e.g. Sonnenburg et al., 2005).

Starch hydrolysis was assayed on ACMP plates supplemented with $0.2 \%(\mathrm{w} / \mathrm{v})$ soluble starch. Starch hydrolysis was not observed for the isolated symbionts, A. facilis or $A$. temperans. Other reference strains were not tested. Gelatinase activity was assayed on ACM medium supplemented with $12 \%(\mathrm{w} / \mathrm{v})$ gelatin. Gelatinase activity was positive for A. facilis and A. temperans, but negative for all eight isolated symbionts. Results for other reference strains were obtained from the literature.

Experiments to define growth factor requirements were conducted on basal defined media (see above) without vitamins. For experiments with free-living species of the genus Acidovorax, $\beta$-hydroxybutyrate replaced D-mannose as the carbon source since some free-living species utilize sugars poorly. Vitamins were supplied as above or added individually at the corresponding concentrations. Amino acids were added at the following final concentrations: glutamate, arginine, aspartate, alanine, valine, threonine $(0.5 \mathrm{mM})$; glutamine, lysine, methionine, asparagine, proline $(0.3 \mathrm{mM})$; and histidine, serine, leucine, tryptophan $(0.2 \mathrm{mM})$. Amino acids were added together, or grouped into six biosynthetic families (Fuchs, 1999) that were then considered as individual treatment units. ACM cultures in mid-exponential growth phase were rinsed with vitaminfree defined medium and transferred into $2.5 \mathrm{ml}$ final volume of fresh vitamin-free defined medium for acclimation and depletion of vitamin traces. After two days, the cultures were inoculated 1:50 into the corresponding treatments.

Biotin alone was required for growth of the novel symbionts in defined media (data not shown). The biotin requirement could be partially alleviated by the addition of a 16-amino acid solution, the addition of aspartate alone, and to a lesser extent by the addition of glutamate (See Supplementary Fig. S3a in IJSEM Online). Of the freeliving Acidovorax strains tested, $A$. defluvii and $A$. temperans displayed a vitamin dependence for growth in defined mineral medium. Biotin partially fulfilled the requirement of the former, but not that of the latter (see Supplementary Fig. S3b). Biotin participates as a cofactor in carboxylating reactions. One such reaction is the anapleurotic replenishment of oxaloacetate into the tricarboxylic acid cycle. When supplied with aspartate, an amino acid that can be converted to oxaloacetate, cells may overcome the need for biotin-dependent carboxylation.

Siderophore production was tested for the isolated symbionts and several reference strains. No siderophore production was detected for the earthworm symbionts. A description of the methods and results is available as Supplementary Material and Supplementary Fig. S4 in IJSEM Online. 
Table 2. Carbon substrate assimilation and other diagnostic tests for isolates of Verminephrobacter eiseniae sp. nov.

Taxa: 1, Verminephrobacter eiseniae sp. nov. ( $n=8$; data from this study); 2, A. avenae subsp. avenae ( $n=24$; Willems et al., 1992); 3, A. konjaci ( $n=3$; Willems et al., 1992); 4, A. defluvii ( $n=8$; Schulze et al., 1999); 5, A. delafieldii ( $n=14$; Willems et al., 1990); 6, A. facilis ( $n=4$; Willems et al., 1990); 7, A. temperans ( $n=18$; Willems et al., 1990); 8, A. valerianellae ( $n=19$; Gardan et al., 2003). +, Present in $90 \%$ of the strains; -, present in $10 \%$ or less of the strains; D, present in 10-90\% of the strains; ND, not determined. Values in parentheses are the results for the proposed type strain EF01-2 ${ }^{\mathrm{T}}$. The following substrates supported the growth of at least six of the eight symbiotic isolates: L-arabinose, D-fructose, D-fucose, L-fucose, Dglucose, D-mannose, D-galactose, D-xylose, D-lyxose, inositol, D-mannitol, glycerol, lactate, acetate, fumarate, $\beta$-hydroxybutyrate, malate, 2 oxoglutarate, pyruvate, succinate, L-alanine, L-asparagine, L-aspartate, L-glutamate, L-glutamine, L-proline. Growth was not supported by the following carbon sources: aconitate, benzoate, citrate, isobutyrate, maleate, L-histidine, L-isoleucine, L-lysine, L-methionine, L-serine, L-threonine, Lvaline, glycine, D-adonitol, L-sorbose, dulcitol, D-sorbitol, $N$-acetylglucosamine, amygdalin, arbutin, aesculin, salicin, D-cellobiose, D-maltose, Dlactose, D-melibiose, sucrose, D-trehalose, inulin, D-melezitose, D-raffinose, starch, glycogen, xylitol, gentiobiose, D-turanose, D-tagatose, L-arabitol, 2-ketogluconate or 5-ketogluconate. Ammonium chloride, urea, L-glutamine, L-glutamate, L-asparagine, L-aspartate, L-alanine, L-arginine, Lornithine, L-serine and sodium nitrate, but not sodium nitrite, served as nitrogen sources when strains were grown on D-mannose.

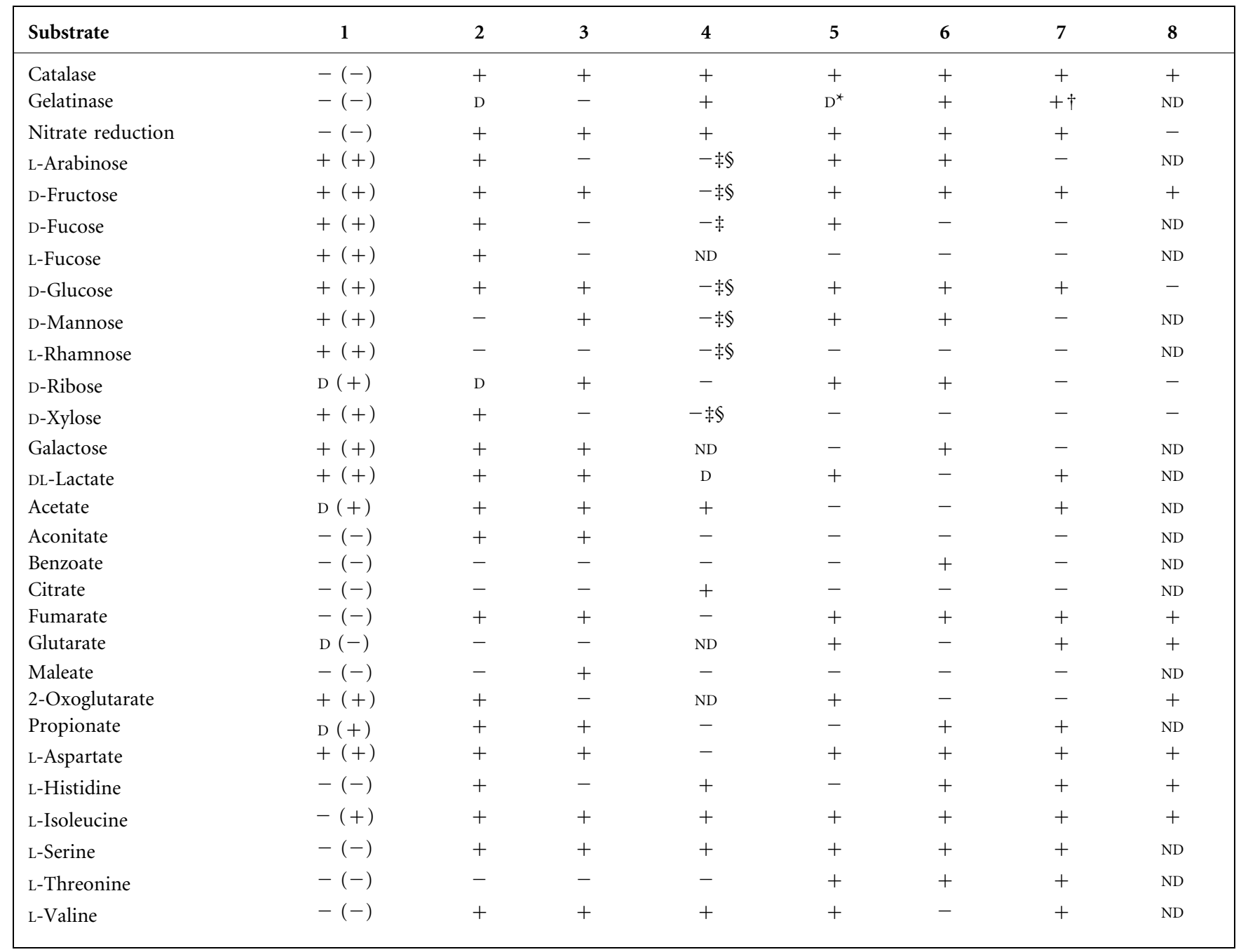

${ }^{\star}$ Data from Willems et al., 1992.

$\dagger$ Also tested in this study, leading to a delayed reaction (previously reported as negative).

$\ddagger$ Data from this study.

\$Schulze et al., 1999.

The values for DNA-DNA hybridization and 16S rRNA gene sequence similarity between the isolated symbionts and the recognized species of the genus Acidovorax firmly establish the novel symbionts as representing a novel species (Stackebrandt \& Goebel, 1994; Stackebrandt et al., 2002). The mean 16S rRNA gene sequence similarity between the earthworm symbionts and either of the other two groups within the genus Acidovorax $(92.5 \pm 0.5 \%$ and 
$93.3 \pm 0.3 \%$ similarity to plant pathogens and other species within the genus, respectively) fell within the range observed at a genus rank (Konstantinidis \& Tiedje, 2005b) and was well below that shared among other species in the genus. Gene phylogenies support the position of the earthworm symbionts as exclusive members of a coherent lineage. A sister taxon to this group cannot be consistently ascertained from the available data. In addition to the molecular differences, our proposal for the creation of a new genus considers the distinctive physiological and ecological features of these organisms to be of taxonomic significance, as has been suggested by others (Konstantinidis \& Tiedje, 2005a; Stackebrandt et al., 2002).

All of the present data indicate that these bacteria have formed a close alliance with earthworms. The molecular data available from symbionts associated with various earthworm species indicate that these bacteria form a cohesive group related to, but distinct from other species of the genus Acidovorax. Their 16S rRNA gene sequence type is rarely detected in surveys of soils or worm culture bedding (see Supplementary Material; S. K. Davidson, M. B. Lund, R. Powell, A. Schramm, D. A. Stahl \& S. James, unpublished data). Further, vertical transmission is probably the sole effective transmission mode (Davidson \& Stahl, 2006), suggesting that bacteria that are shed into the environment encounter a symbiotic dead end. The symbionts' ability to utilize a larger number of sugars than other described related species, their lack of detectable catalase activity, their inability to respire nitrate, their oxygen relationships and their significantly lower growth rate compared with related species are all characteristics that set them apart from other members of the genus Acidovorax. Whole-chromosome differences in genome architecture (unpublished data) further support their evolutionary divergence from the Acidovorax group.

Considering the many distinctive ecological, molecular and physiological characteristics described here, we propose the creation of the genus Verminephrobacter gen. nov. to include the new, nephridia-associated, betaproteobacterial isolates. Since the available comparative datasets do not resolve the branching order of the symbionts relative to described members of the genus Acidovorax, possible paraphyly cannot be excluded. However, deviations from convention to accommodate biological innovation have precedent in systematics (e.g. Adl et al., 2005). The proposed naming reflects the unique ecology of the symbionts and their evolutionary radiation within different earthworm species. We anticipate that this description will provide the basis for future taxonomic revisions of the ecologically and physiologically diverse bacteria now grouped together in the genus Acidovorax.

\section{Description of Verminephrobacter gen. nov.}

Verminephrobacter [Ver.mi.ne.phro'bac.ter. L. n. vermis a worm; Gr. n. nephros a kidney; N.L. masc. n. bacter a rod; N.L. masc. n. Verminephrobacter earthworm-kidney (associated) bacteria].
Cells are straight rods, $1.5 \pm 0.2 \times 0.6 \pm 0.2 \mu \mathrm{m}$. They occur singly or in doublets and are flagellated, but motility is seldom observed under standard culturing conditions. Gram-negative. Oxidase-positive. Catalase-negative. Obligate aerobic growth with a preference for low oxygen tensions. Chemo-organotrophic. Oxidative metabolism occurs with oxygen as the terminal electron acceptor. Dissimilatory nitrate reduction is absent. Moderate growth is obtained on complex media containing pyruvate and amino acids. Ammonium salts, urea and nitrate can serve as nitrogen sources in defined media. Biotin is required for growth on defined mineral medium in the absence of amino acids. A cyclopropane-substituted fatty acid (cyclo $\mathrm{C}_{17: 0}$ ) is present as a major component of membranederived fatty acid methyl esters in all strains tested. The DNA G+C content is $67 \mathrm{~mol} \%$. The genus Verminephrobacter comprises nephridium-associated bacterial symbionts of lumbricid earthworm species. The type species is Verminephrobacter eiseniae.

\section{Description of Verminephrobacter eiseniae sp. nov.}

Verminephrobacter eiseniae (ei.se' niae. N.L. gen. n. eiseniae of Eisenia, a reference to being the nephridial symbiont of the earthworm species Eisenia foetida).

The description is the same as that given for the genus Verminephrobacter. Isolated from platings of nephridial homogenates of the earthworm species Eisenia foetida onto complex media.

The type strain is EF01-2 ${ }^{\mathrm{T}} \quad\left(=\mathrm{ATCC} \quad \mathrm{BAA}-1489^{\mathrm{T}}=\right.$ DSM $19286^{\mathrm{T}}$ ).

\section{Note added on revision}

The description of Acidovorax caeni was published during the late revision stages of this manuscript (Heylen et al., 2008). Data from this paper were incorporated only into Table 1. A. caeni groups with $A$. delafieldii, A. temperans and $A$. defluvii. The $16 \mathrm{~S}$ rRNA gene sequences available for A. caeni show $93 \pm 0.3 \%$ similarity to those of the eight isolates of $V$. eiseniae reported here. The addition of this species to the genus Acidovorax does not alter the conclusions of our work.

\section{Acknowledgements}

N.P. is funded by a Howard Hughes Medical Institute Predoctoral Fellowship and Nasa Astrobiology Institute grant NCC2-1273. This work was in part supported by grants NIH GM 20177, NSF IOB0345049 and NSF DEB0516520. The authors would like to thank Steve MacFarlane for his help with electron microscopy; Dr Andreas Schramm for providing the 'nephridial isolate AT4' nucleotide sequences for multilocus sequence analyses; Dr Ron Walcott for providing A. avenae subsp. citrulli AAC00-1, and two anonymous reviewers for invaluable comments on draft versions of this manuscript. 


\section{References}

Adl, S. M., Simpson, A. G. B., Farmer, M. A., Andersen, R. A., Anderson, O. R., Barta, J. R., Bowser, S. S., Brugerolle, G., Fensome, R. A. \& other authors (2005). The new higher level classification of eukaryotes with emphasis on the taxonomy of protists. $J$ Eukaryot Microbiol 52, 399-451.

Ballinger, M. L., Blanchette, A. R., Krause, T. L., Smyers, M. E., Fishman, H. M. \& Bittner, G. D. (1997). Delaminating myelin membranes help seal the cut ends of severed earthworm giant axons. J Neurobiol 33, 945-960.

Barton, B. M., Harding, G. P. \& Zuccarelli, A. J. (1995). A general method for detecting and sizing large plasmids. Anal Biochem 226, 235-240.

Bousfield, I. J., Smith, G. L., Dando, T. R. \& Hobbs, G. (1983). Numerical analysis of total fatty acid profiles in the identification of coryneform, nocardioform and some other bacteria. J Gen Microbiol 129, 375-394.

Cole, J. R., Chai, B., Marsh, T. L., Farris, R. J., Wang, Q., Kulam, S. A., Chandra, S., McGarrell, D. M., Schmidt, T. M. \& other authors (2003). The Ribosomal Database Project (RDP-II): previewing a new autoaligner that allows regular updates and the new prokaryotic taxonomy. Nucleic Acids Res 31, 442-443.

Davidson, S. K. \& Stahl, D. A. (2006). Transmission of nephridial bacteria of the earthworm Eisenia fetida. Appl Environ Microbiol 72, 769-775.

Ezaki, T., Hashimoto, Y. \& Yabuuchi, E. (1989). Fluorometric deoxyribonucleic acid-deoxyribonucleic acid hybridization in microdilution wells as an alternative to membrane filter hybridization in which radioisotopes are used to determine genetic relatedness among bacterial strains. Int J Syst Evol Microbiol 39, 224-229.

Felsenstein, J. (1989). PHYLIP - phylogeny inference package (version 3.2). Cladistics 5, 164-166.

Fuchs, G. (1999). Biosynthesis of Building Blocks. In Biology of the Prokaryotes, pp. 127-134. Edited by J. W. Lengeler, G. Drews \& H. G. Schlegel. Stuttgart: Thieme.

Fuchs, G. \& Kröger, A. (1999). Growth and Nutrition. In Biology of the Prokaryotes, pp. 88-109. Edited by J. W. Lengeler, G. Drews \& H. G. Schlegel. Stuttgart: Thieme.

Gardan, L., Dauga, C., Prior, P., Gillis, M. \& Saddler, G. S. (2000). Acidovorax anthurii sp. nov., a new phytopathogenic bacterium which causes bacterial leaf-spot of anthurium. Int J Syst Evol Microbiol 50, 235-246.

Gardan, L., Stead, D. E., Dauga, C. \& Gillis, M. (2003). Acidovorax valerianellae sp. nov., a novel pathogen of lamb's lettuce [Valerianella locusta (L.) Laterr.]. Int J Syst Evol Microbiol 53, 795-800.

Grogan, D. W. \& Cronan, J. E. (1997). Cyclopropane ring formation in membrane lipids of bacteria. Microbiol Mol Biol Rev 61, 429-441.

Guckert, J. B., Hood, M. A. \& White, D. C. (1986). Phospholipid esterlinked fatty acid profile changes during nutrient deprivation of Vibrio cholerae: increases in the trans/cis ratio and proportions of cyclopropyl fatty acids. Appl Environ Microbiol 52, 794-801.

Heylen, K., Lebbe, L. \& De Vos, P. (2008). Acidovorax caeni sp. nov., a denitrifying species with genetically diverse isolates from activated sludge. Int J Syst Evol Microbiol 58, 73-77.

Hoshino, T., Terahara, T., Tsuneda, S., Hirata, A. \& Inamori, Y. (2005). Molecular analysis of microbial population transition associated with the start of denitrification in a wastewater treatment process. J Appl Microbiol 99, 1165-1175.

Knop, J. (1926). Bakterien und Bakteroiden bei Oligochäten. Z Morph Ökol Tiere 6, 588-624 (in German).
Könneke, M. \& Widdel, F. (2003). Effect of growth temperature on cellular fatty acids in sulphate-reducing bacteria. Environ Microbiol 5, 1064-1070.

Konstantinidis, K. T. \& Tiedje, J. M. (2005a). Genomic insights that advance the species definition for prokaryotes. Proc Natl Acad Sci U S A 102, 2567-2572.

Konstantinidis, K. T. \& Tiedje, J. M. (2005b). Towards a genomebased taxonomy for prokaryotes. J Bacteriol 187, 6258-6264.

Ludwig, W., Strunk, O., Westram, R., Richter, L., Meier, H., Yadhukumar, Buchner, A., Lai, T., Steppi, S. \& other authors (2004). ARB: a software environment for sequence data. Nucleic Acids Res 32, 1363-1371.

Manefield, M., Griffiths, R. I., Leigh, M. B., Fisher, R. \& Whiteley, A. S. (2005). Functional and compositional comparison of two activated sludge communities remediating coking effluent. Environ Microbiol 7, $715-722$.

Marmur, J. (1963). A procedure for the isolation of deoxyribonucleic acid from microorganisms. Methods Enzymol 6, 726-738.

Mesbah, M., Premachandran, U. \& Whitman, W. B. (1989). Precise measurement of the $\mathrm{G}+\mathrm{C}$ content of deoxyribonucleic acid by highperformance liquid chromatography. Int J Syst Evol Microbiol 39, 159-167.

Muyzer, G., de Waal, E. C. \& Uitterlinden, A. G. (1993). Profiling of complex microbial populations by denaturing gradient gel electrophoresis analysis of polymerase chain reaction-amplified genes coding for 16S rRNA. Appl Environ Microbiol 59, 695-700.

Ramsay, J. A. (1949). The site of formation of hypotonic urine in the nephridium of Lumbricus. J Exp Biol 26, 65-75.

Schramm, A., Davidson, S. K., Dodsworth, J. A., Drake, H. L., Stahl, D. A. \& Dubilier, N. (2003). Acidovorax-like symbionts in the nephridia of earthworms. Environ Microbiol 5, 804-809.

Schulze, R., Spring, S., Amann, R., Huber, I., Ludwig, W., Schleifer, K.-H. \& Kämpfer, P. (1999). Genotypic diversity of Acidovorax strains isolated from activated sludge and description of Acidovorax defluvii sp. nov. Syst Appl Microbiol 22, 205-214.

Schweitzer, B., Huber, I., Amann, R., Ludwig, W. \& Simon, M. (2001). $\alpha$ - and $\beta$-proteobacteria control the consumption and release of amino acids on Lake Snow aggregates. Appl Environ Microbiol 67, 632-645.

Scott, D. A. \& Musgrave, A. J. (1971). Aspects of fine structure of symbiotes and related host tissues in nephridia of Allolobophora caliginosa typica (Annelida - Lumbricidae). J Invertebr Pathol 18, 51-60.

Smibert, R. M. \& Krieg, N. R. (1994). Phenotypic characterization. In Methods for General and Molecular Bacteriology, pp. 607-654. Edited by P. Gerhardt, R. G. E. Murray, W. A. Wood \& N. R. Krieg. Washington, DC: ASM Press.

Sonnenburg, J. L., Xu, J., Leip, D. D., Chen, C.-H., Westover, B. P., Weatherford, J., Buhler, J. D. \& Gordon, J. I. (2005). Glycan foraging in vivo by an intestine-adapted bacterial symbiont. Science 307, 1955-1959.

Stackebrandt, E. \& Goebel, B. M. (1994). Taxonomic note: a place for DNA-DNA reassociation and $16 \mathrm{~S}$ rRNA sequence analysis in the present species definition in bacteriology. Int J Syst Evol Microbiol 44, 846-849.

Stackebrandt, E., Frederiksen, W., Garrity, G. M., Grimont, P., Kampfer, P., Maiden, M., Nesme, X., Rossello-Mora, R., Swings, J. \& other authors (2002). Report of the ad hoc committee for the reevaluation of the species definition in bacteriology. Int J Syst Evol Microbiol 52, 1043-1047. 
Thompson, J. D., Higgins, D. G. \& Gibson, T. J. (1994). CLUSTAL W: improving the sensitivity of progressive multiple sequence alignment through sequence weighting, position-specific gap penalties and weight matrix choice. Nucleic Acids Res 22, 4673-4680.

Willems, A., Falsen, E., Pot, B., Jantzen, E., Hoste, B., Vandamme, P., Gillis, M., Kersters, K. \& De Ley, J. (1990). Acidovorax, a new genus for Pseudomonas facilis, Pseudomonas delafieldii, E. Falsen (EF) Group 13, EF Group 16, and several clinical isolates, with the species Acidovorax facilis comb. nov., Acidovorax delafieldii comb. nov., and Acidovorax temperans sp. nov. Int J Syst Evol Microbiol 40, 384-398.
Willems, A., Goor, M., Thielemans, S., Gillis, M., Kersters, K. \& De Ley, J. (1992). Transfer of several phytopathogenic Pseudomonas species to Acidovorax as Acidovorax avenae subsp. avenae subsp. nov., comb. nov., Acidovorax avenae subsp. citrulli, Acidovorax avenae subsp. cattleyae, and Acidovorax konjaci. Int J Syst Evol Microbiol 42, 107-119.

Willems, A., Doignon-Bourcier, F., Goris, J., Coopman, R., de Lajudie, P., De Vos, P. \& Gillis, M. (2001). DNA-DNA hybridization study of Bradyrhizobium strains. Int J Syst Evol Microbiol 51, 1315-1322. 